Emergent identity formation and the co-operative: Theory building in relation to alternative organizational forms

Teresa Nelson, Ph.D. (corresponding author)

Simmons College School of Management

300 The Fenway Boston, MA 02115, USA

e: Teresa.nelson@simmons.edu t: 1-978-595-6098

Dylan Nelson

Ph.D. Student, Sociology Department, University of Michigan

500 S. State Street, Ann Arbor, MI 48109-1382, USA

dknelson@umich.edu

Benjamin Huybrechts, Ph.D

HEC Management School, University of Liege

Sart Tilman B33 Bte 4, 4000 Liege, Belgium

b.huybrechts@ulg.ac.be

Frédéric Dufays

$\mathrm{Ph}$.D. Student, HEC Management School, University of Liege

Sart Tilman B33 Bte 4, 4000 Liege, Belgium

f.dufays@ulg.ac.be

Noreen O'Shea, Ph.D.

Novancia Business School

3 Rue Armand Moisant, 75015 Paris, France

noshea@novancia.fr

Giorgia Trasciani

Ph.D. Student, HEC Management School, University of Liege

Sart Tilman B33 Bte 4, 4000 Liege, Belgium

giorgia.trasciani@gmail.com

Authors notes:

- The co-authors together identify as the Juniper Co-operatives Research Group affiliated with the Centre for Social Economy at the University of Liege.

- This research has been carried out in part under the framework of an Inter-university Attraction Pole funded by the Belgian Science Policy Office under the title 'If not for Profit, for What, and How?' 


\title{
Emergent identity formation and the co-operative: Theory building in relation to alternative organizational forms
}

\section{Key words:}

organizational identity

identity formation

co-operative

alternative organizational forms

organizational ecology

\begin{abstract}
How are identities of alternative forms of organization constructed and how does this process differ relative to normative forms socially expected? In this research we consider identity formation in co-operatives, a population of organizations allied globally through values and practices such as democratic participation, voluntary and open membership, and limited return to capital investment. As an extension of current thinking on identity formation in entrepreneurship and organizational theory, we use co-operatives to explore social expectations and institutional arrangements around form at the societal, population, and organizational levels using a population ecology framework. We develop a research agenda based on propositions that address specific features of identity formation in less typical forms of organization, including tensions with normative business expectations, engagement with identity audiences, embeddedness in networks and alliances, structural factors influencing identity, and identity ambiguity.
\end{abstract}




\section{INTRODUCTION}

We propose that the distinctive global code of the co-operative organization, constituting both values and practice (e.g., democratic member control, voluntary and open membership), influences identity development, identity expression, and strategic positioning. We believe this work, in developing propositions and suggesting a research agenda, extends and enriches research on identity formation in entrepreneurship and organization theory in two ways. First, we provide discussion on co-operatives as an organizational form that has been persistent $(150+$ years) and yet unconventional in developed, capitalist economies over that time. Normative to some audiences and unconventional, innovative, or unknown to others, co-operatives emerge with procedures in place that set them apart, at least partially, from normative business practice. Second, with the co-operative form as a guide, we explore how the typicality of organizational form may influence organizational identity formation more generally. Using a population ecology lens informed by social construction, we take identity as a set of expectations around rule maintenance determined by social interactions and shared cognitions of audiences.

Work in entrepreneurship has tended to assign the work of identity formation to founders and the founding team: identity is developed and then shared, for example, with internal and external stakeholders as an early step in establishing a venture's relationships with key partners and in positioning vis-a-vis competitors (e.g., Eisenhardt and Schoonhoven 1990). The founder role is emphasized due to role features such as longest organizational tenure, heightened psychological commitment, structural authority, and ownership stake (Nelson 2010). Organization theory scholars, however, particularly in the area of organizational ecology and institutional theory, have drawn a broader, more inclusive, and less rigid boundary for identity creators to encompass 
institutions and audiences beyond founders, owners, and employees (Kreiser, Patel, and Fiet 2013; Carmichael, Jenkins, and Brulle 2012). He and Brown (2013: 6) state that 'while most studies in organizational identity have focused on internal processes of identity formation, it is increasingly evident that identities are formed in part by dialogue with external stakeholders and are best construed as relational and comparative'.

Our work integrates institutional theory with the rules for identity formation, finding a gap as regards unusual organizational forms. Their examination provides clarity for the whole. Cooperatives are relatively small in total number and economic power (see section to follow) and their category of organization receives less attention from the media, from business and government institutions, and from the suppliers of hierarchy-oriented managers, i.e., business schools. Therefore, identity formation is more complicated: co-operatives must define and enact their values while embedded in a system with which they are more or less at odds.

Operating primarily and philosophically outside of the profit to capital owners' model, cooperatives sit differently in the economic institutional environment and in relation to domain members; while they may be dedicated to an alternate form, their cognitive orientation and to some degree their practical operations are influenced by the dominant logic of the for-profit capitalist business model which they experience continually (Kim 2014). Conflicts, interactions, or a lack of internal understanding of co-operative values in relation to traditional business values create ambiguity in identity as co-operatives move in a broadly recognized normative system. This ambiguity may be more or less influential on identity formation and maintenance. Co-operatives share this position with other unusual organizational forms in the business sphere including social enterprise and its different expressions, some recently innovated, such as B- 
Corps (for more on the legitimacy challenges of non-conventional forms in the social enterprise space see: Dart 2004, Nicholls 2010; Huybrechts and Nicholls 2013; Huybrechts, Mertens, and Rijpens 2014). This exploration is also salient for non-profits and charities, for example, who have been encouraged of late to adopt business models to promote productivity (Dart 2004) as well as for other unusual forms of for-profit enterprise, like family businesses, that also hold multiple codes of identity at their core.

The article begins with a review of the co-operative as an organizational category to explicate its unique history and politics as well as its features and values. Next, concepts from organizational ecology around identity are used to motivate a discussion of identity formation for co-operatives as an atypical organizational form. A co-operative model of identity formation is complicated from the base model and presented here through propositions to inform future research regarding tensions with normative business expectations, engagement with identity audiences, embeddeness in alliances and networks, structural mechanisms influencing identity, and network implications. Collective dynamics through co-operative networks that may cause aggregate changes in the co-operative sector and provoke strategy changes at the organizational level are considered. We also explore how identity ambiguity arises due to conflicts over identity expectations, and how this ambiguity may be overcome or exacerbated in relation to domain participants such as suppliers, workers and customers. Finally, we discuss the ways that our model of identity formation for co-operatives adds to existing theory and suggests future scholarship. Our hope is that this work encourages greater inquiry into co-operatives and other atypical forms, presents co-operatives as an entrepreneurial option, and advises practitioners on the positioning of identity in practice to promote their organization's survival and growth. 


\section{CO-OPERATIVES}

The co-operative organizational form emerged through a series of entrepreneurial experiments in the United States, Canada, and England during the first half of the $19^{\text {th }}$ century. In 1844, twentyeight workers founded the Rochdale Society of Equitable Pioneers in Lancashire, England to counter the poverty induced by the Industrial Revolution. This was the first successful modern co-operative business, balancing a values-driven inward focus with external market competition (Zamagni and Zamagni 2010). According to its statutes, 'the objects and plans of this Society are to form arrangements for the pecuniary benefits and the improvement of the social and domestic conditions of the members' (Holyoake 1893/1900, 11), which constitutes an exception in the business landscape with regard to claimed organizational identity. Other types of economic cooperation in the nineteenth century were modeled across Europe including the labor co-operative in France (1831), the credit co-operative (or credit union or mutual bank) in Germany (1852), and the farmers' co-operative in Denmark (1882) (Zamagni and Zamagni 2010). Each initiative aimed to provide a different service within the economy, yet their adherence to the principles laid out collectively by the Rochdale Pioneers linked them across the continent and the Atlantic.

To support this wave of innovation internationally, and to link like-minded members, the International Co-operative Alliance (ICA) was founded in 1895. The ICA adopted the seven principles laid down by the original Rochdale Society, making the Society the founder of the modern co-operative movement. The ICA also upholds a Statement on Co-operative Identity, the latest revision of which was endorsed by the ICA membership in 1995, defining a co-operative as: 
'an autonomous association of persons united voluntarily to meet their

common economic, social, and cultural needs and aspirations through a jointly owned and democratically controlled enterprise....(Co-operatives are...) based on the values of self-help, self-responsibility, democracy, equality, equity and solidarity. In the tradition of co-operative founders, co-operative members believe in the ethical values of honesty, openness, social responsibility and caring for others.' Co-operative Identity Statement, International Co-operative Alliance, 2014

As details in Table 1 illustrate, the original fundamental co-operative principles have remained essentially and remarkably unchanged over 150 years. Generally, these principles are adopted at the birth of the organization and implemented continually through espoused ideology and practice.

INSERT TABLE 1 ABOUT HERE

Under the umbrella of values shared by co-operative organizations there is significant variation among groups of co-operatives relative to organizing type (consumer, producer, worker), sector of activity (e.g., agriculture, credit, technology production, retail, social welfare provision, housing) and political orientation (i.e., the degree of participation in the values and actions of a capitalist economy and/or reformist commitment). Furthermore, the degree of historical embeddedness of the co-operative form varies by region both within Europe and elsewhere. Higher concentrations of co-operatives are found in, for instance, Northern Italy (Borzaga and Santuari 2001), the Québec region (Malo and Vézina 2004), and several Spanish regions such as 
Almeria and the Basque country (Giagnocavo 2012). This variation in the density of local cooperative networks shapes both salience of the co-operative business model and the opportunities for inter-cooperation. Though this regional variation overall may complicate the identity formation process, there are national and international meta-organizations that provide an information and ideology sharing platform allowing co-operatives to respond to, morph, oppose and reconcile to (as deemed necessary or advantageous) normative business practice over time (Paranque and Willmott 2014).

As both the cause and result of regional and national variation in the prevalence of co-operatives, laws and regulations pertaining to co-operatives differ across countries (Cracogna, Fici, and Henrÿ 2013) and even across areas within countries (e.g., the U.S. manages business formation rules and reporting by state rather than federally). The ICA reports representing close to one billion individual members joined through their 272 member organizations in 94 countries (International Co-operative Alliance 2014). Still, the percentage of co-operatives to total business organizations is small. Despite the difficulty in collecting and comparing international statistics (International Co-operative Alliance and Euricse 2013), Sanchez Bajo and Roelants (2011) note that for economies representing nearly $75 \%$ of world GDP, co-operatives contribute around $5 \%$ of total. Research has shown that over time, the emergence of co-operatives appears to occur in waves (Boone and Özcan 2014), driven by co-operative networks in relation to social movements, with a higher rate of co-operatives emerging during periods marked by strong ideological contestation. In this research we focus on co-operatives developed in capitalist economies recently ${ }^{1}$ while recognizing the historical roots of co-operatives and the influence of

\footnotetext{
${ }^{1}$ This excludes co-operatives engaged in subsistence livelihoods in the developing world, co-operatives founded as part of socialist nations' economic development, as well as labor efforts resulting in organizations founded in the last century.
} 
time on the posture and position of the current form. The following section develops a theoretical framework based on organizational ecology to explain how organizational identity and legitimacy issues may explain inter alia the adoption of the co-operative form in such valueladen contexts.

\section{THEORY}

\section{Organizational identity from an ecological perspective}

In population ecology, form is a central construct that delineates the boundary of an organizational population; it is a kind of collective identity that is a 'typification of commonality' (Hsu and Hannan 2005: 477). This commonality rests in the identities of member organizations that share a meaningful social code that is distinctive from other populations (Hannan and Freeman 1977).

At the organizational level, identity is the essence of form as expressed through code. A code, or rule set, specifying the identity, is prescribed by an audience made up of agents who hold 'an interest in a domain and control over material and symbolic resources that affect the success and failure of the claimants on the domain' (Hsu and Hannan 2005: 477). Agents may include parties both 'internal' and 'external' to an organization, as traditionally defined. Identity in this view rests intrinsically with the audience rather than the organization (Pólos, Hannan, and Carroll 2000).

Codes may become institutionalized by an audience and hence become its default expectation for organizational features and behavior (Baron 2001) - through institutionalization it creates an 
expectation of adherence that can become a blind eye. Pratt and Foreman (2000) suggest this institutionalization in relation to the code operates as a gestalt, rather than a checklist, as audiences assess coherence and adherence through cognitive processes such as discourse. The strategies identified by Pratt and Foreman (2000) to manage multiple identities are relevant to alternative organizational forms facing audiences with diverging codes. However, from a social constructionist perspective, managerial agency is limited as codes lie with audiences and cannot easily be manipulated. Moreover, as a socially constructed phenomena, identity at the individual organization and population level can be seen to be continually forming, at varied pace, in relation to audience engagement and environment conditions. This lens differs from other conceptual models of organizational identity which place a strong demarcation between identity formation and identity change (Gioia et al. 2013). Indeed, as identity is constantly evolving together with audiences, it is forming and changing continually to a certain extent, although phases of relative stability can be identified depending on the convergence of audiences and the institutionalized nature of their codes.

Organizations may have multiple audiences and the degree to which these audiences agree on the rules for the organization in question is a measure of institutional consolidation (Battilana and Dorado 2010; Glynn 2000). Full institutional consolidation is rare and most organizations manage some identity ambiguity, taken here to mean not only uncertainty about the future but also an inexactness of meaning, lack of clarity, and even the possibility of interpreting a future state in two or more distinct ways.

Scholars differ in their opinions about the effect of identity ambiguity as it emerges due to multiple applied codes from multiple audiences of an organization. Such ambiguity may make 
environments, populations, audiences and agents more difficult to negotiate and manage (Battilana and Dorado 2010; Tracey, Phillips, and Jarvis 2011) such as when identity codes are not synergistic. Other researchers see ambiguity as a potential positive, for example, as a hedge (Jay 2013) or as a justification for change or a lack of clarity (Ashforth and Reingen 2014) leading to lessened sanctions. Pratt and Foreman (2000) suggest that multiple identities can be managed. They present a taxonomy of strategies along two axes: 1) how many identities an organization has to deal with, and 2) how synergistic these identities are. The four strategies they recognize are: deletion (low number of identities, low synergy), compartmentalization (high number of identities, low synergy), integration (low number of identities, high synergy), and aggregation (high number of identities, high synergy).

In general, meaningful codes, aggregated across organizations, result in a form that establishes membership rules for the population (Phillips and Zuckerman 2001). Research shows that organizations that are not validated as members of the population to which they nominally belong suffer performance challenges (Zuckerman 1999). Institutionalization of the form has been related to growth and higher numbers of member organizations, the general acceptance of labels to define the population (e.g., the 'co-op'), and the identification by organizations of their collective identity. Phillips and Zuckerman (2001) argue that high status organizations have less of a need to conform to population form demands because their individual as opposed to collective identity is stronger.

\section{Theoretical extensions: The atypical form in reference to the co-operative}


In this section we discuss theoretial extensions regarding atypical forms in relation to the cooperative at the meta-level (values and legitimacy), population level (typicality) and organizational level (governance and membership rules).

Meta-level: values and legitimacy. Population ecology allows us to consider a nested set of identity formation influences operating at the macro, population, and organization levels. At the macro (societal) level, Thornton, et al. (2012) identify 7 overarching institutional orders including family, state, religion, profession, corporation, community and market (see also Friedland and Alford 1991) that can be taken to hold a pervasive influence on population and organizational identity constructions. These social orders will fundamentally influence the populations and organizations that are nested beneath.

Powerful organizational audiences in control of resources (e.g., money, mindshare, media, among others) in capitalist based economies today maintain and enforce normative standards related to business practice on a global, national, and local level. Though not legally prescribed, the profit-generating return to shareholders model of business is normative. It is held to be the way things are and should be. Therefore standard operating rules are enforced from above and below (by agents) and organizations adopt roles and behavior in response. These responses can vary across culture, time and circumstance (e.g, degree of typicality - see below) and they influence population and organizational identities in fundamental ways.

In comparison, co-operatives are an atypical kind of business organization. Rather than prioritizing returns to shareholders, co-operatives prioritize benefits for members (e.g. lower prices and/or higher quality in consumer co-operatives), limited distribution of residuals among members, and decision-making power not proportional to the number of shares owned (in the 
purest case 'one member, one vote' instead of 'one share, one vote'). Co-operatives are distinguished from other categories of organizations as well by their allegiance to a specific set of values, exemplified by the Rochdale Principles. These seven co-operative values are formally elaborated, interrelated, grassroots empowered, intentionally subscribed, and considered the global standard for co-operative operation.

While empirical research studies on co-operatives from the population dynamics perspective remain scarce, findings highlight the difficulties co-operatives encounter in trying to uphold these identity-driven values as they evolve in competitive environments. For example, Boone \& Özcan (2014) provide some evidence that external competition from corporations can contribute to both co-operative survival and demise. Studying founding processes of co-operatives in the U.S. ethanol industry from 1973 to 2013, the authors found that co-operatives thrive in those locations where a co-operative ideology is firmly entrenched, itself fuelled by an anti-corporate climate which empowers local farmers to mobilize resources and energy against the supremacy of the dominant economic actors. Conversely, in the absence of such an identity-driven, locallysituated ideology, findings show that co-operative foundings decrease. Schneiberg (2013) and Schneiberg, King, and Smith (2008) have also observed that the prevalence of anti-corporate social movements in given regions has had an important impact on the salience of co-operative movements and thus on the formation and consolidation of co-operatives locally. The population ecology perspective is thus useful to better understand collective dynamics through co-operative networks that may cause aggregate changes in the co-operative sector in given places and periods of time. 
While atypical, co-operatives are not isolated from standard business organizations; together they share general organizational rules, operating systems (e.g., distribution, transportation, telecommunications) and human resources (e.g., customers, workers, suppliers). Social values may bridge the divide as well (e.g. social responsibility, community engagement). At the same time, certain co-operative rules are antithetical to standard business practice, i.e., member-owning as opposed to shareholding. As the less powerful form embedded in a system that takes standard business values and practice as the norm, co-operatives are challenged to maintain their idiosyncratic rules against pressure to conform.

In Table 2 we specify some of these shared and opposing rules of co-operatives and standard business, relative to a third category, general organizational form (to include non-profits, for instance). Our goal is not to specify all the sets of possible shared code but simply to establish how rules may be shared, synergistic, or in conflict, how this creates complications for audiences and organizations, and to suggest how normative influence may be experienced.

\section{INSERT TABLE 2 ABOUT HERE}

Table 2 demonstrates that co-operatives and business organizations do not stand simply in opposition in regard to organizational features and values; their division is not clean cut conceptually or practically. The survival of co-operatives likely depends on their ability to compete with other business types (Birchall 2013) with threats to their identity exacerbated in times of economic difficulty or transformation. Somerville (2007) has underlined the potential 
conflict to co-operative identity that can be generated when the principle of membership ownership and control is abandoned or when the exercise of internal democracy is weakened.

Population level: Typicality. The normative-atypical dynamic examines organizational form in relation to the concepts of cognitive legitimacy, i.e. the knowledge and 'taken-for-grantedness' of the form in audiences' eyes (Suchman 1995). As Huybrechts and Mertens (2014: 201) point out, 'cooperatives do not represent a taken-for-granted organizational model and are rarely associated with a given field or activity'. This lack of cognitive legitimacy due to their atypicality places co-operatives in a risky space in which they may lack the support from audiences (e.g. banks, governments, consumers, etc.) that do not recognize or understand the specific features of their form.

Conceptualizing typicality directly, we propose its consideration as a continuous variable that is given meaning contextually, symbolically, geographically, chronologically. If one takes 'typical' to be what is expected, and 'atypical' to be what is not expected (and therefore unusual), atypical can be understood as an assessment of similarity between some unit and another unit or units; it is a categorization process involving representation. Vosniadou and Ortony (1989) define two general approaches to understanding similarity in terms of categorization: (1) face similarity versus deep similarity and (2) global similarity versus dimensional similarity. While a full exposition on typicality is beyond the scope of this article, we do want to suggest some of the ways 'atypical' can be conceptualized and how it might vary when considering the co-operative form.

1) Typicality and information flows and cognitive attention. This case deals with the degree of difference from the norm that is and can be perceived by audience members accurately. Here 
we are considering the availability and reliability of information flows and cognitive attention. For example, defining features of the co-operative may be fairly invisible to an engaged party either because the evidence of such features are 'behind the scenes' or because the features have not been made particularly visible. On the other hand, those engaged with the co-operative, regardless of how visible the distinguishing features of the co-operative, may not be capable of distinguishing co-operative or normative identity features or they may rather mindlessly not give the information their attention. For example, in the latter case, a retail food co-operative may look and act like a 'regular' food store to some people, perhaps in part because identity features of the co-operative form are not central to the person's experience of picking up some milk and butter. In another case, the political orientation of the co-operative, say a workers co-operative, may be a de-facto gate of entrance to business dealings with the organization as information and distinguishing features are strongly cued and enforced.

2) Typicality and geographic network density and familiarity. A generally atypical form may be less unusual in certain geographic locations due to historical record and remembrance and/or an unusual density of co-operatives in operation (e.g., as above: Spain, Italy generally; also by industry, for example, agricultural co-operatives in the U.S.).

3) Typicality and degree of variety. Where other alternative forms exist perceptually, whatever their exact form, alternative forms can be more likely expected. Conversely, where the normative standard is pervasive, alternatives become generally less expected (Ruef and Patterson 2009).

4) Typicality and agent, organizational and social alignment with co-operative values. Varying ideologies of nations, regions, cultures, religions, political and sociological orientations, etc., 
may hold values aligned with, or opposed to, some or all of co-operative values, their underlying beliefs, and/or with the causes associated with them. Alignment of values in these cases will soften illegitimacy claims while opposition will harden them. Broadly, for example, the global human rights movement has a sympathetic orientation to co-operative ideals from the standpoint of equity concerns.

It is important to acknowledge that regardless of challenges, some atypical organizations do persist and even thrive (Miller and Chen 1996). Some even become new models of what is normal and expected (Leblebici and Salancik 1989).

\section{Organization level: Membership and governance rules}

The co-operative identity can also be considered at the organization level where any differing values among co-operatives may be mirrored in different ownership and governance structures. The organizational structure induces specific relationships with audiences which in turn may shape or constrain their influence on organizational identity formation because of the claims they are entitled to make on the organization (see Table 3). The implications for investors and members will be discussed and compared with standard business firms.

INSERT TABLE 3 ABOUT HERE

First, shareholders as the dominant stakeholder category for standard business firms concentrate the two dimensions of ownership rights: the right to claim the organization's residual income 
(profits) and the right to make decisions in proportion of the shares they hold (Milgrom and Roberts 1992). Any deviation from standard business values by managers, for example making decisions that negatively affect profit levels, can be expected to be sanctioned by shareholders.

In co-operatives, the capital is brought by the members who are the suppliers, consumers, and/or workers; in essence these parties are the investors and they wear a 'double hat'. However, if holding more shares in the co-operative does not give more decision-making rights, and if the returns on investment are limited, as is theoretically the case in co-operatives, then the 'investor' side of the 'double hat' will remain accessory to the principal status of supplier, consumer or worker. When the capital is opened to external investors (who do not have other relationships with the organization), only investors sympathetic to co-operative values are likely to be attracted unless standard business governance rules are enforced.

Second, regarding members, the 'double hat' is likely to reinforce the adoption and resilience of co-operative values and practices, hence strengthening the co-operative identity of the organization. Indeed, decisions regarding the allocation of profits are likely to be guided not only with an investor's logic, in any case constrained by co-operative governance rules, but also following the logic of the members' status. Workers, for example, are likely to prioritize organizational stability as a result of their employment status. Likewise, consumers may prioritize high-quality products or lower prices over higher returns.

Yet, even when downplaying the salience of an investor's logic, the members may be tempted to consider only their economic relationship with the co-operative and the benefits that they can gain in this relationship thanks to their influence on organizational decision-making. They therefore may pull the organizational identity away from co-operative values specifically in 
relation to their transactional roles with the organization. For example, workers may be tempted to raise salaries, consumers to lower prices, and suppliers to increase prices, thereby prioritizing individual interests over co-operative identity. Two avenues are available to co-operatives to help overcome this phenomenon: a strong insistence on participation in the governance structures and the involvement of multiple stakeholders in the governance system to mutually enforce adherence to co-operative values and practices. Each of these avenues will be further developed in the propositions section.

\section{PROPOSITIONS}

In this section, we generate propositions on co-operatives as an atypical organizational business form from an organizational ecology perspective. We have so far nuanced a model of identity formation that recognizes (1) the influence of audiences in integrating the normative model of standard business in parallel or in competition with co-operative values and practices; (2) the influence of the economic transactional role in the relationship of audiences with the cooperative; (3) the importance of network embeddedness and alliances for atypical forms; (4) the role of membership and governance rules in organizational coherence ; and (5) the challenge of overcoming identity ambiguity. In Figure 1 below, we lay out our proposition map with the goal of articulating organizational identity in the case of co-operatives with these five elements.

As shown in Figure 1, all the propositions involve factors that help explain a common 'dependent variable', i.e, the formation of a co-operative identity. The initial factors (on the left) refer to how the prioritization of co-operative values by organizational audiences (including other co-operatives in the context of a network; proposition 3) are likely to influence co- 
operative identity formation. The alignment of audiences in terms of adherence to co-operative values is considered in relation to both business values (proposition 1) and to their economic role with regard to the co-operative (proposition 2). The influence of audiences and networks however, is likely to be 'filtered' by internal factors such as the type of co-operative (consumer, supplier, worker, or a multi-stakeholder combination) and its specific governance and membership rules (proposition 4).

Moving to the right in Figure 1, the capacity of the co-operative members to overcome potential identity ambiguity induced by audiences and to construct an internally and externally consistent co-operative identity is potentially mediated by three 'ambiguity-resolving' factors (proposition 5). The mediating role of propositions 4 and 5 is indicated with the help of dotted-line boxes in Figure 1. These propositions do not intend to be exhaustive of the possible influences on identity formation in atypical organizational forms. Rather, we intend to pave the way for future empirical research examining the avenues for identity formation in atypical organizational forms in general and the co-operative form in particular.

INSERT FIGURE 1 ABOUT HERE

\section{Proposition 1: Audience alignment in terms of business versus co-operative values}

Because of their embeddedness in a social system that assumes standard business as the norm, co-operatives may be assigned business rules by key audiences by rote (the alternate case would not be expected to occur). Population ecology allows us to consider a nested set of identity 
formation influences operating at the meta, population, and organization level. At the meta- level (societal), Thornton, et al. (2012) identify 'market' and 'corporation' as key influences on population, and therefore organizational level activity. These social orders will fundamentally influence the populations and organizational identities nested within. Different sorts of influences may be related to how standard business and atypical co-operative values are held.

In Table 3 we considered this in relation to types of co-operatives - consumer, producer, and worker - vis-à-vis key audiences of consumers, suppliers and workers. Each type of co-operative also operates beyond that group with other key audiences that may or may not specify cooperative rules for the organization. Taken cumulatively, these codes delivered by consumers, suppliers, and workers may or may not strengthen the co-operative identity, generating or assuaging organizational ambiguity.

Co-operative audiences deliver codes to the co-operative that can vary cumulatively at the organizational level in regards to expectations around the enactment of co-operative values versus standard business values (see Table 3). Such cumulative variance, we propose, will impact the degree of identity ambiguity experienced by the co-operative. Cumulative variance in audience codes can be measured by the degree of similarity of code across the co-operative's audiences, i.e., horizontal consolidation, in terms of co-operative and standard business values.

PROPOSITION 1a: The more a co-operative organization's audience codes are horizontaly consolidated in terms of co-operative values, the stronger the co-operative's identity adherence to co-operative values.

The development of population and organizational rules within a form can take a top-down or bottom-up approach, or some position along that spectrum. Organizations may ally through joint 
understandings by their audiences over critical rules of action and behavior and a population of organizations may evolve and come to be understood as a form over time (Hannan and Freeman 1977). Alternatively, in the case of co-operatives, the essential rules for form membership are historically prescribed, and though open to amendment at the population level, and subject to enforcement at the organization and population level, the rules have survived largely intact for over a century. In most cases co-operatives have evolved as legally distinct from standard forprofit businesses. On formation as legal entities, founding members select co-operative and associated legal rules together with social rules that dwell within and amongst the population both formally and informally.

Implications of this top-down identity code process are substantial both in terms of the development of organizational identity and for the persistence of the population level identity. For the latter, the influences of the International Co-operative Alliance network and of the Rochdale Principles are pervasive. This influence acts as a vertical consolidation force on regional and individual co-operative identity. At the organizational level, this consolidation provides a range of network effects including information flows, solidarity, practical business relationships (buyer, supplier, worker) and affective links to people who are or will become members of co-operative audiences through alignment with co-operative values.

PROPOSITION 1b: The more a co-operative organization's audience codes are horizontally consolidated in terms of business values, the more identity ambiguity for the co-operative. 
Another type of variety felt by co-operatives in terms of codes received relates to the range of codes received across standard business and co-operative audiences. A wider range is proposed to lead to higher levels of organizational ambiguity.

PROPOSITION 1c: The wider range of audience code elements from co-operative values and standard business values, the more identity ambiguity for the co-operative.

Various activities of a co-operative are more or less central to the organization. Centrality as used here means central or core to mission as well as central to activity flow and engagement. For instance, in the case of a worker's co-operative, using a broad generalization for illustration purposes, financial management may be less central than worker management in both senses of centrality. With this orientation, we posit that when standard business code delivered to the cooperative is isolated from the core, its impact on the organization's adherence to co-operative identity will be minimized.

PROPOSITION 1d: The more isolated the practice of standard business values derived from audience codes from the central activities of the co-operative, the stronger the co-operative's identity adherence to co-operative values.

Proposition 2: Audience alignment in terms of economic role versus co-operative values

Audiences form in relation to their interaction with the organization (Hsu and Hannan 2005) yet their allegiance to the co-operative may exist additionally, for example, ideologically. A member may relate to the co-operative through their role as a customer exclusively, for example, and/or their alignment can be based on the values they share with the organization in a non-transactional 
way. This leads to recognition that outside forces beyond the immediate economic role

relationship may cause audiences to coalesce on certain expectations for the co-operative.

The particular audiences of customers, suppliers, and workers for a co-operative may vary in

their degree of commitment to co-operative values and this may inform their degree of influence

on identity formation vis-à-vis standard business practices in those cases where business values

and co-operative values are in conflict. Considering a consumer co-operative style, for instance,

when a co-operative seeks to transform its customers into active members and they face passivity

or reluctance from these customers, the relevance of democratic decision-making may be

questioned internally, leading to identity ambiguity.

PROPOSITION 2a: When a co-operative's identity forming audience is aligned around cooperative values over role values, the identity adherence to co-operative values will be stronger.

PROPOSITION 2b: When a co-operative's identity forming audience is aligned with cooperative values over role values, ambiguity around identity adherence to co-operative values will be weaker.

In Table 3 we considered the membership of the co-operative - whether it is composed of consumers, producers, workers, or a combination. When one of these categories owns the cooperative, their commitment to co-operative values and practices is likely to be stimulated especially if these values are adapted in a way that resonates with their specific role. For example, if workers see participation in decision-making as an avenue to improve their working conditions and enhance their motivation, their adherence to co-operative values will be reinforced. 
PROPOSITION 2c: Within types of co-operatives (worker, consumer, supplier), the better the alignment of co-operative code values with the central member activity of the co-operative, the stronger the co-operative's identity adherence to co-operative values.

\section{Proposition 3: Embeddedness in co-operative networks}

Co-operatives may be identified as a movement given shape through affiliation and subscription to principles jointly held (Schneiberg 2013). Co-operatives are intended to seek out co-operative suppliers, customers, and employees to conduct business and they participate in regional, national and international networks of co-operatives. However, co-operatives are not segregated within the economy and as an alternative business form they do business with non-co-operatives to satisfy business demands. We posit that the level of commitment to co-operative values will be influenced by the number and strength of ongoing relationships with other co-operatives as compared with non-co-operative businesses. The more members build a strong co-operative identity inside their organization, the more likely they are to support other co-operatives beyond their sole economic interests, thereby creating cooperative identity-reinforcing spill-over effects.

PROPOSITION 3a: The higher the level of embeddedness of a co-operative with other cooperatives in networks of suppliers, customers and workers, the stronger the co-operative's cooperative identity value adherence.

PROPOSITION 3b: The higher the level of embeddedness of a co-operative in alliances of co-operatives, the stronger the co-operatives identity value adherence.

Hsu and Hannan (2005) present the concept of 'horizontal institutional consolidation' as the condition under which the values of multiple audiences align in the creation of an organizational identity. We present the concept of vertical institutional consolidation here. Vertical 
institutional consolidation relates to the degree of engagement of co-operatives in the population and meta-level organizational networks that espouse shared values.

PROPOSITION 3c: The higher the level of vertical embeddedness of a co-operative in alliances of co-operatives (i.e., regional, national and global level), the stronger the cooperatives identity value adherence.

Further, it can be argued that when a co-operative is aligned with the co-operative movement at a macro-organizational level (e.g., regional, national, global), they are more likely to valorize the identity codes of audiences also aligned with co-operative values. The system of identity formation is a multi-level system phenomenon (Brown 2001); audience hierarchies are created when a strong, non-normative system of values is active and exercised through vertical institutional consolidation.

PROPOSITION 3d: The higher the level of vertical embeddedness of a co-operative in alliances of co-operatives (i.e., at the regional, national and global level), the stronger the valorization of a co-operative's identity audiences with codes prioritizing co-operative values.

Proposition 4: The mediating role of membership and governance rules

Among the core features that are stressed by alliances of co-operatives are specific membership and governance rules. However, the way in which each co-operative interprets these rules and translates them into practice may strongly differ and thereby influence the process of identity formation. More particularly, the enforcement of co-operative rules that limit profit distribution and give equal voting rights to all members regardless of the number of shares held is likely to attract members who are sensitive to co-operative values and discourage investors whose priority 
is owner returns. If however these rules are softened, for example if voting rights are allowed to accumulate in proportion to shares owned, or if constraints on returns are abandoned, then 'classical' investors following standard business values may be attracted. The literature documents several examples of co-operatives in which this phenomenon has been observed, leading to the dilution of co-operative identity over time (Bager 1994, Zamagni and Zamagni 2010).

PROPOSITION 4a: The more a co-operative restricts ownership rights, i.e. the more it limits profit distribution and applies the 'one member, one vote principle', the less likely investors guided by profit motives will intervene and impose standard business values in the identify formation process.

Even without external investors, co-operative members may be tempted to prioritize their own interests (as consumers, suppliers or workers) at the expense of organizational development of the co-operative identity. One governance mechanism for overcoming this potential dilution of the co-operative identity is the reinforcement of participation of members in governance, for example by stimulating Board turnover, by adding participation committees and events beyond the sole General Assembly, and/or by involving members through regular communication and consultation (Cornforth 2004; Spear, Cornforth, and Aiken 2009). Such increased participation of members is likely to generate commitment to the organization and to its sustainability. Furthermore, participatory governance may strengthen members' beliefs in the superiority of the co-operative model as they take part in strategic decision-making, hence reinforcing the adoption of co-operative values and practices.

PROPOSITION 4b: The more a co-operative stimulates the participation of members in organizational governance, the more likely co-operative values and practices will be favored in identity construction. 
The other governance avenue likely to foster co-operative identity is the structural inclusion of varied audiences, e.g. organic food co-operatives involving producers, consumers, and/or workers in their governance mechanisms. Multi-stakeholdership, despite bringing additional governance challenges (Spear, Cornforth, and Aiken 2009; Huybrechts, Mertens, and Rijpens 2014), involves a mutual control among the various audience categories that is likely to foster the prioritization of co-operative values and practices as a common identity vector. Additionally, it is a way to reduce the risks of opportunistic behavior by one audience category as decisions are put in the hands of a majority of members of varied roles (Ebrahim, Battilana, and Mair 2014; Huybrechts, Mertens, and Rijpens 2014). The democratic governance principle in such cases facilitates the reinforcement of the co-operative identity.

PROPOSITION 4c: The more a co-operative involves diverse audience categories in its governance structures, the stronger the likelihood of positively influencing the co-operative identity.

\section{Proposition 5: Overcoming identity ambiguity}

Co-operatives, as an atypical organizational form operating within a normative business values system, express standard business values and co-operative values as part of operational practice. When codes rooted in different values are neutral or complementary, they may be expressed compatibly (e.g., the quality of goods and services is important). However, when identity audiences deliver codes that are conflicting (e.g. enhance value to shareholders v. oppose the existence of shareholders), identity ambiguity results. 
Pratt and Foreman (2000) propose that the level of ambiguity in identity formation is based on the number of identities managed and the level of synergy among those identities. To this we add a third dimension, the degree of interaction of the conflicting audiences (seen in Proposition 1d), and a fourth, the degree to which the conflicting values can be constructed as compatible.

We propose that conflicting identity codes may be managed by the co-operative recognizing and responding to audiences intentionally and selectively; co-operatives may act as shape shifters, using their co-operative identity and their business identity with different audiences, in different situations, at different times. They may also reconcile, to a greater or lesser extent, initially conflicting codes to lessen identity dubiety. This ability is described in similar terms in the literature on hybrid organizations as ventures respond to multiple and potentially conflicting institutional demands (Pache and Santos 2013).

For unusual organizational forms, ambiguity around identity, arising from multiple conflicting identity codes that cannot be reconciled, can lead to audience confusion, lower levels of support, and thus lower performance (Ginzel, Kramer, and Sutton 1999; Golden-Biddle and Rao 1997). However, we suggest that an alternate path for co-operatives is to 'show the proper face' to 'the proper audience' (McDonnell and King 2013; Dutton and Dukerich 1991) avoiding sanctioning when values conflict (Pache and Santos 2013). Co-operatives can use their co-operative and business features and practices at different points in the value chain with different populations of interested parties, perhaps even at different times, and in different venues. Finally, they can work to build bridges between apparently conflicting values through a process of sensemaking and negotiation. 
Strategic posturing of this sort would not be relevant in the normative case of organizational form where 'horizontal institutional consolidation' (Hsu and Hannan 2005) of values is considered identity strengthening. The result of such identity ambiguity management, when successfully practiced, may allow the co-operative to realize success, which may take the form of enhanced survival, growth rates over time, and financial performance.

Some hints about the conditions for overcoming identity ambiguity in atypical organizational forms include Battilana and Dorado's work (2010) which shows that socialization and hiring practices can take multiple identities into account in order to avoid value conflict within the organization. Thus, ambiguity is more likely to be managed strategically in the case of cooperatives when employees and members are familiar with both co-operative and business values and practices through their education, socialization, and/or training. Pache and Santos (2013) suggest that conflicts over the means of operation should follow attempts to build bridges of values at the field level. Further, in the case of co-operatives, they will be more capable of combining co-operative and business identities where networks provide them with templates and successful cases of such combination.

PROPOSITION 5a: Identity ambiguity for the co-operative is more likely to be overcome with lower levels of horizontal institutional consolidation.

PROPOSITION 5b: Identity ambiguity is more likely to be overcome when co-operative members and employees have been educated and socialized to both co-operative and business values and practices.

PROPOSITION 5c: Identity ambiguity is more likely to be overcome when co-operatives receive templates and examples on how to successfully combine co-operative and business identities from the co-operative network.

\section{DISCUSSION}


The goals of this paper are to explore, heighten attention, and inspire future empirical research on identity formation in co-operatives and other unusual organizational forms through discussion of theory, consideration of the atypical case, and by the development of propositions to lead ideas and projects.

The value of this work derives from the contrast between normative and atypical organization forms, and how the values and actions they ascribe to organizations through codes may conflict or exist neutrally or in synergy. We have explored how this contrast can be enriched by considering the dimensions of what is 'typical' contextually, symbolically, geographically, chronologically. We propose a series of propositions that explore how identity ambiguity arises and is felt: non-normative forms cannot build their identity in a homogeneous setting and identity ambiguity is inevitable (Kodeih and Greenwood 2014).

We have also considered how identity ambiguity can potentially be realized and managed at the organizational and population level. Using organizational ecology audience-based identity theory, we show how institutional conditions and dynamics, and cognitive structures, values and historical and geographic realities shape co-operative situation and strategy. For example, how taken-for-granted ideas about form can create a blind eye to code adherence and how audience ability to perceive, and the mindshare agents give this activity, play a role in how the values of the alternative form are realized. The situation of co-operatives, joined by a global values code usually assumed at organizational birth, will allow rich exploration of these ideas regarding atypical organizational forms and how resultant institutional conflicts can be resolved.

This inquiry leaves us better informed on how, following a social constructionist perpective, identity formation for alternative organizational forms necessarily relies on dialectical processes 
in which the organization integrates the values, codes and assessment criteria of various audiences (Kroezen and Heugens 2012). While vertical consolidation can be pursued through participating in the broader co-operative movement for instance, it is unlikely that co-operatives can count only other co-operatives or sympathetic agents as their audiences.

In terms of audiences, our propositions distinguish not only economic role differences (suppliers, consumers, workers) but also differences in values and social relationships that are likely to have an impact on identity formation. While this is certainly true for alternative forms such as cooperatives, it may also be valid for established business forms for which audiences codes may differ, for example, in terms of social responsibility expectations (Lee 2011). Rather than assuming certain audience roles with certain values, our propositions take into account how roles and values interact and become ordered. This construction may also be applied to business corporations, for instance, by exploring the different ways shareholders balance profit distribution and social responsibility expectations: in this case delivering codes to the corporation. These ideas suggest a strategic approach to code management that differs from that construed for typical organizations: ambiguity may be an organizational asset.

Importantly, this code process is not conscious, formal, or rationalized. Audience members individually and collectively do not list values and ideal features in an inventory fashion. Codes are 'default' in the Hsu and Hannan (2005) model: they arise organically and are socially constructed. Considering this process from the perspective of a co-operative holding atypical values of a clearly delineated type, we see a complication within the commonly asserted mechanisms of identity formation. This leads to a better understanding of identity formation in new ventures generally (Kroezen and Heugens 2012). 
Our study of co-operatives also extends the range of messages available to organizations to signal code compliance or code reinterpretation to include features that are specific to alternative organization types (Besharov and Smith 2014). One of these messages is governance, which is expected to be democratic for co-operatives (Spear 2004; Cornforth 2004). Values and codes set by audiences may embed the identity formation process in the organization not only in terms of the products or services offered, and by relations with audiences and society as a whole, but also in terms of internal processes. These internal processes have not been a focus of research but are gaining attention with the increasing focus on corporate governance in the aftermath of notorious governance scandals (Vlessert 1999).

Beyond the formation and reinterpretation of identity codes, the channels through which the codes are signaled to audiences is key. These channels include formal and informal reporting, websites, customer/supplier interactions, and personal interactions. The channel will be determined by the relationship of the audience to the firm, including the attentionn and understanding flowing between, and by the perceived consequences of the message flow. This dynamic is ripe for further investigation.

Further on code messaging, more work is needed to understand how audiences react to code violations: are resources retained? Is legitimacy damaged? Under what conditions? For cooperatives, and other atypical organizational forms, context may be critical. There may be geopolitical differences, as well as differences related to economic conditions. When identity ambiguity leads to code violation for certain audiences but not for others, an interesting question is how these audiences exercise power and who is effective in realizing organziational response. Such power may not just be a function of who holds the functional resources but may also 
depend on the audience's strategic importance, their networks, the inter-relationships of audiences, and value alignment.

We find the study of the co-operative form to be instructional to our understanding of all forms: comparison often clarifies the logic of both cases. With inherent conflicting messages about identity flowing into the co-operative, we can see how organizations puzzle over and reconcile conflicting demands (which exist to some extent for all organizations). We also see how vertical as well as horizontal consolidation of messages can have an impact in identity formation - this finding is relevant to all emerging and emergent ventures and thus to the entrepreneurship literature in general. Theoretically, we have considered how the boundaries of an organizational population may be necessarily clouded and dynamic as conflicting identity demands position an organization. Audiences will vary by role, values, power, and networking strength. These will all be features that an alternate form, and perhaps every form, will need to take into account and manage to achieve their purposes.

Another focus of this work is to show how identity ambiguity can be strategically managed and how it may lead to a strong identity when the different codes and values are assembled in such a way that organizational members experience consistency. While this ability has been described in the emerging literature on hybrid organizations (Battilana and Lee 2014; Battilana and Dorado 2010), our propositions offer a more fine-grained picture of codes and values as micro-level identity building blocks as compared with broader institutional logics (Besharov and Smith 2014). Moreover, in the co-operative case, the focus is not so much how elements from established forms can be combined into a new hybrid form, but rather how resemblance with and differentiation from dominant forms (Navis and Glynn 2011) can be managed when constructing 
the identity of a purposefully alternative form. In other words, rather than seeing organizational categories as neutral reservoirs of codes and values available to any newly created organization, our propositions reintroduce power and politics to show how identity is negotiated through interactions with more or less receptive audiences. There is good work to be done here moving forward.

Finally, we address the practitioner side and our desire to raise the discussion of co-operatives and other alternate forms of organization in the context of our world today. Ambiguity can be considered in relation to isomorphism (DiMaggio and Powell 1983). Through coercive, mimetic, and normative pressures, the dominant economic paradigm has remained centered on the corporation in this century, a theoretical claim supported by the proportion in number, size, or market capitalization. However, recent research by Kim (2014) proposes a conscious logic of anti-isomorphism driving the governance structure decisions of entrepreneurs who have decided not to align themselves with an investor-seeking logic.

The level of political engagement and of non-normative orientations to capitalist production among co-operatives varies considerably. In a cross-state study of co-operative business diffusion, Schneiberg (2013) argues that standard institutional diffusion processes are amplified or inhibited by the presence of anti-corporate social movement activity. Perhaps this variation can also be understood as a result of founder political identity. Co-operatives and other atypical forms (e.g. family firms or more recent B-corp and other social enterprise forms) may be challenged economically due to their peculiarities and a struggle to maintain their values as they move toward the norm may result. Others move left with strong political orientations tied to global movements for income equity and environmental protection, for instance. Continued work 
in this area is necessary to understand how such organizations are positioned in the business world, and what degrees of freedom they hold to vary from the norm and still achieve their organizational objectives.

As an immediate outcome of this work in terms of future research, and in relation to the first two propositions, studies could examine and compare audiences of different atypical organizations to assess the salience of non-normative (e.g. co-operative) codes and values over both standard business values and role values (e.g. buyer-seller relationships). Research examining how the organizations and their main audiences dialogue with regard to these codes and values, and how this dialogue shapes the identity formation process, would be extremely valuable. Further, studies could address the discursive and symbolic devices through which this dialogue takes place.

On the set of ideas included in proposition three, it would be interesting to explore the influence of alliances and networks of atypical organizational forms on the identity formation process, for example, by comparing how organizations vary in their involvement in alliances and network, and the impact of same. Longitudinal research before, during, and/or after such involvement could provide valuable insights. Organizations facing similar sets of audiences and network, but employing different ownership and governance models, could also be studied. This would enable scholars to assess the filtering role of ownership and governance in mediating the interaction with audiences. Longitudinal studies could consider how changes in governance may alter these interactions and affect identity formation.

Regarding proposition set five, research could specifically target the issue of identity ambiguity and how it can be managed in atypical organizational forms. In particular it could be asked: how 
is identity ambiguity experienced in similar organizations (e.g. in the same sector) and what are the specific and/or combined effects of horizontal consolidation, education and socialization, and network involvement on ambiguity management, and ultimately on identity formation? Further, how do, and could atypical organization managers strategically consider and enact identity ambiguity? Finally, to account for the feed-back effects illustrated in Figure 1, empirical studies could be designed to explore how atypical organizations, individually and collectively, experience identity in their daily inter-organizational interactions and how this may affect audience perceptions and expectations. At the regional level, it would be relevant to examine how concentrations of atypical forms (e.g. co-operatives in the Basque region) may affect public awareness and therefore the sense of what is typical. Where is the practical and theoretical divide between typical and atypical, and if a spectrum, what impacts can be felt, and when. This could be investigated via media attention and through coverage in academic business curricula, for instance.

\section{CONCLUSION}

Our work has considered identity formation dynamics in co-operatives as an emblematic case of the atypical organizational form. Serving as the basis for future qualitative and quantitative work, we believe these ideas have the potential to enrich the literatures on identity formation, entrepreneurship, and organizational forms in various ways. Focusing on a minority yet symbolically divergent case, we work to extend the scope of empirical models on which these research streams rely providing increased connection with the evolving complexity of contemporary organizational taxonomies. 
Perhaps for all organizations, but maybe especially for atypical forms, the tension to fit in and to remain distinctive is pressing. How organizational members perceive, negotiate, and strategize this tension can relate directly and indirectly to organizational performance. Morever, the lens of population ecology, with a focus on inter- and intra-organizational effects and relaitonships, highlights a mechanism for establishing legitimacy among varied audiences encountered in the operational and strategic domains, leading to a construction of organizational identity that serves those performance goals. The combination of the institutional pressures felt from the meta level on atypical organizations, together with the task of constructing identity felt at the organizational and population level, provides a continual project of identity formation that we do not expect to be resolved, but rather to be reconciled continually.

\section{References}

Ashforth, Blake E., and Peter H. Reingen. 2014. "Functions of Dysfunction: Managing the Dynamics of an Organizational Duality in a Natural Food Cooperative." Administrative Science Quarterly.

Bager, Torben. 1994. "Isomorphic Processes And The Transformation Of Cooperatives." Annals of Public and Cooperative Economics 65 (1):35-59.

Baron, David P. 2001. "Private politics, corporate social responsibility, and integrated strategy." Journal of Economics and Management Strategy 10:7-45.

Battilana, Julie, and Silvia Dorado. 2010. "Building sustainable hybrid organizations: the case of commercial microfinance organizations." Academy of Management Journal 53 (6):14191440.

Battilana, Julie, and Matthew Lee. 2014. "Advancing Research on Hybrid Organizing - Insights from the Study of Social Enterprises." The Academy of Management Annals 8 (1):397441. 
Besharov, Marya L., and Wendy K. Smith. 2014. "Multiple institutional logics in organizations: Explaining their varied nature and implications." Academy of Management Review 39 (3):364-381.

Birchall, Johnston. 2013. "The Potential of Co-Operatives During the Current Recession: Theorizing Comparative Advantage." Journal of Entrepreneurial and Organizational Diversity 2 (1):1-22.

Boone, Christophe, and Serden Özcan. 2014. "Why do cooperatives emerge in a world dominated by corporations? The diffusion of cooperatives in the U.S. bio-ethanol industry, 1978-2013." Academy of Management Journal 57 (4):990-1012.

Borzaga, Carlo, and A. Santuari. 2001. "Italy: from Traditional Co-operatives to Innovative Social Enterprises." In The Emergence of Social Enterprise, edited by Carlo Borzaga and Jacques Defourny, 166-181. Routledge: London.

Brown, Andrew D. 2001. "Organization studies and identity: Towards a research agenda." Human Relations 54 (1):113-121.

Carmichael, Jason T., J. Craig Jenkins, and Robert J. Brulle. 2012. "Building environmentalism: The founding of environmental movement organizations in the United States, 19002000." The Sociological Quarterly 53 (3):422-453.

Cornforth, Chris. 2004. "The Governance of Cooperatives and Mutual Associations: a Paradox Perspective." Annals of Public and Cooperative Economics 75 (1):11-32.

Cracogna, Dante, Antonio Fici, and Hagen Henrÿ, eds. 2013. International handbook of cooperative law. Heidelberg: Springer Verlag.

Dart, Raymond. 2004. "The legitimacy of social enterprise." Nonprofit Management \& Leadership 14 (4):411-424.

DiMaggio, Paul J., and Walter W. Powell. 1983. "The Iron Cage Revisited: Institutional Isomorphism and Collective Rationality in Organizational Fields." American Sociological Review 48 (2):147-160.

Dutton, Jane E., and Janet M. Dukerich. 1991. "Keeping an eye on the mirror: Image and identity in organizational adaptation." Academy of Management Journal 34 (3):517-554.

Ebrahim, A., J. Battilana, and J. Mair. 2014. "The governance of social enterprises: Mission drift and accountability challenges in hybrid organizations." Research in Organizational Behavior.

Eisenhardt, Kathleen M., and Claudia Bird Schoonhoven. 1990. "Organizational growth: Linking founding team, strategy, environment, and growth among U.S. semiconductor ventures, 1978-1988." Administrative Science Quarterly 35 (3):504-529. 
Friedland, Roger, and Robert R. Alford. 1991. "Bringing Society Back In." In The New Institutionalism in Organizational Analysis, edited by Walter W. Powell and Paul J. DiMaggio. Chicago: The University of Chicago Press.

Giagnocavo, Cynthia. 2012. Support for Farmers' Cooperatives: Country Report Spain. Wageningen: University of Wageningen.

Ginzel, Linda E., Roderick M. Kramer, and Robert I. Sutton. 1993. "Organizational impression managemnt as a reciprocal influence process: The neglected role of the organizational audience." Research in Organizational Behavior 15:227-266.

Gioia, Dennis A., Shubha D. Patvardhan, Aimee L. Hamilton, and Kevin G. Corley. 2013. "Organizational Identity Formation and Change." The Academy of Management Annals 7 (1):123-193.

Glynn, Mary Ann. 2000. "When Cymbals become Symbols: Conflict over Organizational Identity within a Symphony Orchestra." Organization Science 11 (3):285-298.

Golden-Biddle, Karen, and Hayagreeva Rao. 1997. "Breaches in the boardroom: Organizational identity and conflicts of commitment in a nonprofit organization." Organization Science 8 (6):593-611.

Hannan, Michael T., and John Freeman. 1977. "The population ecology of organizations." American Journal of Sociology 82 (5):929-964.

He, Hongwei, and Andrew D. Brown. 2013. "Organizational Identity and Organizational Identification: A Review of the Literature and Suggestions for Future Research." Group \& Organization Management 38 (1):3-35.

Holyoake, George Jacob. 1893/1900. The history of the Rochdale pioneers. 3rd ed. London: Swan and Sonnenschein.

Hsu, Greta, and Michael T. Hannan. 2005. "Identities, genres, and organizational forms." Organization Science 16 (5):474-490.

Huybrechts, Benjamin, and Sybille Mertens. 2014. "The relevance of the cooperative model in the field of renewable energy." Annals of Public \& Cooperative Economics 85 (2):193212.

Huybrechts, Benjamin, Sybille Mertens, and Julie Rijpens. 2014. "Explaining stakeholder involvement in social enterprise governance through resources and legitimacy." In Social Enterprise and the Third Sector: Changing European Landscapes in a Comparative Perspective, edited by Jacques Defourny, Lars Hulgard and Victor Pestoff. London \& New York: Routledge. 
Huybrechts, Benjamin, and Alex Nicholls. 2013. "The Role of Legitimacy in Social EnterpriseCorporate Collaboration." Social Enterprise Journal 9 (2):130-146.

International Co-operative Alliance. 2014. ICA Factsheet. Brussels: ICA.

International Co-operative Alliance and Euricse. 2013. The world co-operative monitor 2013: Exploring the co-operative economy.

Jay, Jason. 2013. "Navigating Paradox as a Mechanism of Change and Innovation in Hybrid Organizations." Academy of Management Journal 56 (1):137-159.

Kim, Suntae. 2014. "Entrepreneurial imagination in Detroit: Anti-isomorphic construction of alternative logic." 109th American Sociological Association Annual Meeting, San Francisco, August 16-19, 2014.

Kodeih, Farah, and Royston Greenwood. 2014. "Responding to Institutional Complexity: The Role of Identity." Organization Studies 35 (1):7-39.

Kreiser, Patrick M., Pankaj C. Patel, and James O. Fiet. 2013. "The influence of changes in social capital on firm-founding activities." Entrepreneurship Theory and Practice 37 (3):539-568.

Kroezen, Jochem J., and Pursey P. M. A. R. Heugens. 2012. "Organizational identity formation: processes of identity imprinting and enactment in the dutch microbrewing landscape." In Constructing Identity in and around Organizations - Perspectives on Process Organization Studies, edited by M. Schultz, S. Maguire, A. Langley and H. Tsoukas, 89127. Oxford: Oxford University Press.

Leblebici, H., and G. Salancik. 1989. "Definition of organizations and managerial role: An empirical examination of a Weberian legacy." Organization Studies 10:301-325.

Lee, Min-Dong. 2011. "Configuration of External Influences: The Combined Effects of Institutions and Stakeholders on Corporate Social Responsibility Strategies." Journal of Business Ethics 102 (2):281-298.

Malo, Marie-Claire, and Martine Vézina. 2004. "Governance and Management of Collective User-Based Enterprises: Value-Creation Strategies and Organizational Configurations." Annals of Public \& Cooperative Economics 75 (1):113-137.

McDonnell, Mary-Hunter, and Brayden King. 2013. "Keeping up appearances: Reputational threat and impression management after social movement boycotts." Administrative Science Quarterly 58 (3):387-419.

Milgrom, Paul, and John Roberts. 1992. Economics, Organization and Management. Englewood Cliffs: Prentice Hall International. 
Miller, D., and M. Chen. 1996. "Nonconformity in competi- tive repertoires: A sociologi- cal view of markets." Social Forces 74:1209-1234.

Navis, Chad, and Mary Ann Glynn. 2011. "Legitimate Distinctiveness and the Entrepreneurial Identity: Influence on Investor Judgments of New Venture Plausibility." Organization Studies 36 (3):479-499.

Nelson, Teresa. 2010. "The role and influence of firm founders." In Handbook of Top Management Teams, edited by Frank Bournois, Jérôme Duval-Hamel, Sylvie Roussillon and Jean-Louis Scaringella, 263-269. New York: Palgrave Macmillan.

Nicholls, Alex. 2010. "The Legitimacy of Social Entrepreneurship: Reflexive Isomorphism in a Pre-Paradigmatic Field." Entrepreneurship Theory and Practice 34 (4):611-633.

Pache, Anne-Claire, and Felipe Santos. 2013. "Inside the Hybrid Organization: Selective Coupling as a Response to Competing Institutional Logics." Academy of Management Journal 56 (4):972-1001.

Paranque, Bernard, and Hugh Willmott. 2014. "Cooperatives_-saviours or gravediggers of capitalism? Critical performativity and the John Lewis Partnership." Organization 21 (5):604-625.

Phillips, Damon J, and Ezra W Zuckerman. 2001. "Middle-Status Conformity: Theoretical Restatement and Empirical Demonstration in Two Markets." American Journal of Sociology 107 (2):379-429.

Pólos, Laszlo, Michael T. Hannan, and Glenn R. Carroll. 2000. Foundations of a theory of social forms. Rotterdam: ERIM, Erasmus Research Institute of Management.

Pratt, Michael G., and Peter O. Foreman. 2000. "Classifying Managerial Responses to Multiple Organizational Identities." The Academy of Management Review 25 (1):18-42.

Ruef, Martin, and Kelly Patterson. 2009. "Credit and classification: The impact of industry boundaries in nineteenth-century America." Administrative Science Quarterly 54 (3):486520.

Sanchez Bajo, Claudia, and Bruno Roelants. 2011. Capital and the debt trap: Learning from cooperatives in the global crisis. New York: Palgrave Macmillan.

Schneiberg, Marc. 2013. "Movements as Political Conditions for Diffusion: Anti-Corporate Movements and the Spread of Cooperative Forms in American Capitalism." Organization Studies 34 (5-6):653-682.

Somerville, Peter. 2007. "Co-operative identity." Journal of Co-operative Studies 40 (1):5-17. 
Spear, Roger. 2004. "Governance in Democratic Member-Based Organisations." Annals of Public and Cooperative Economics 75 (1):33-59.

Spear, Roger, Chris Cornforth, and Mike Aiken. 2009. "The governance challenges of social enterprises: evidence from a UK empirical study." Annals of Public and Cooperative Economics 80 (2):247-273.

Suchman, Mark C. 1995. "Managing Legitimacy: Strategic and Institutional Approaches." Academy of Management Review 20 (3):571-610.

Thornton, Patricia H., William Ocasio, and Michael Lounsbury. 2012. The Institutional Logics Perspective: A New Approach to Culture, Structure, and Process. Oxford: Oxford University Press.

Tracey, Paul, Nelson Phillips, and Owen Jarvis. 2011. "Bridging Institutional Entrepreneurship and the Creation of New Organizational Forms: A Multilevel Model." Organization Science 22 (1):60-80.

Vlessert, Henk. 1999. "A Matter of Balance: On Corporate Governance and Strategy of the Rabobank." Finish Journal of Business Economics 4:511-524.

Vosniadou, Stella, and Andrew Ortony, eds. 1989. Similarity and Analogical Reasoning. New York: Cambridge University Press.

Zamagni, Stefano, and Vera Zamagni. 2010. Cooperative enterprise: Facing the challenge of globalization. Cheltenham: Edward Elgar.

Zuckerman, Ezra W. 1999. "The Categorical Imperative: Securities Analysts and the Illegitimacy Discount." American Journal of Sociology 104 (5):1398-1438. 
Table 1: The evolution of global co-operative principles

\begin{tabular}{|c|c|c|c|}
\hline $\begin{array}{c}\text { ROCHDALE } \\
\text { PIONEERS } \\
\text { PRINCIPLES (1844) }\end{array}$ & $\begin{array}{c}\text { ICA } 4 \\
\text { PRINCIPLES } \\
(1937)\end{array}$ & $\begin{array}{c}\text { ICA } 6 \\
\text { PRINCIPLES } \\
(1966)\end{array}$ & $\begin{array}{c}\text { ICA } 7 \\
\text { PRINCIPLES } \\
(1995)\end{array}$ \\
\hline $\begin{array}{c}\text { Ideological neutrality and } \\
\text { tolerance }\end{array}$ & $\begin{array}{c}\text { Open } \\
\text { membership }\end{array}$ & $\begin{array}{l}\text { Voluntary } \\
\text { membership }\end{array}$ & $\begin{array}{c}\text { Voluntary and open } \\
\text { membership }\end{array}$ \\
\hline $\begin{array}{c}\text { Democratic government } \\
\text { (one person, one vote) } \\
\text { women too could be } \\
\text { voting members }\end{array}$ & $\begin{array}{l}\text { Democratic } \\
\text { control }\end{array}$ & Democracy & Democratic control \\
\hline $\begin{array}{l}\text { End-year rebate } \\
\text { proportional to purchases }\end{array}$ & $\begin{array}{l}\text { Dividend paid } \\
\text { according to } \\
\text { business done }\end{array}$ & $\begin{array}{l}\text { Distribution of } \\
\text { surplus }\end{array}$ & $\begin{array}{l}\text { Member economic } \\
\text { participation }\end{array}$ \\
\hline $\begin{array}{c}\text { Minimum interest on } \\
\text { loans }\end{array}$ & $\begin{array}{l}\text { Limited interest } \\
\text { on capital }\end{array}$ & $\begin{array}{l}\text { Limited interest on } \\
\text { share capital }\end{array}$ & $\begin{array}{l}\text { Autonomy and } \\
\text { independence }\end{array}$ \\
\hline \multicolumn{4}{|l|}{$\begin{array}{c}\text { Freedom of purchasing } \\
\text { outside the co-op }\end{array}$} \\
\hline \multicolumn{4}{|l|}{$\begin{array}{l}\text { Sale for cash at fixed } \\
\text { prices }\end{array}$} \\
\hline & & $\begin{array}{l}\text { Provision for } \\
\text { education }\end{array}$ & $\begin{array}{l}\text { Education, training } \\
\text { information }\end{array}$ \\
\hline & & $\begin{array}{c}\text { Cooperation among } \\
\text { co-operatives }\end{array}$ & $\begin{array}{c}\text { Cooperation among } \\
\text { co-operatives }\end{array}$ \\
\hline & & & $\begin{array}{l}\text { Concern for } \\
\text { community }\end{array}$ \\
\hline
\end{tabular}


Table 2: Neutrality, conflict and synergy among rules of business, the co-operative and general organization

\begin{tabular}{|c|c|c|c|}
\hline RULES & \begin{tabular}{|l|} 
General \\
Organization
\end{tabular} & Business & Co-operative \\
\hline \multicolumn{4}{|l|}{ Standard Organizational } \\
\hline Survival & $\checkmark$ & $\checkmark$ & $\checkmark$ \\
\hline $\begin{array}{l}\text { Adherence to the law governing the } \\
\text { organization }\end{array}$ & $\checkmark$ & $\checkmark$ & $\checkmark$ \\
\hline Accomplish goals; be productive & $\checkmark$ & $\checkmark$ & $\checkmark$ \\
\hline \multicolumn{4}{|l|}{ Standard Business } \\
\hline Provide value to customers & $\begin{array}{l}\text { neutral- } \\
\text { conflictual }\end{array}$ & $\checkmark$ & synergistic \\
\hline Separation of ownership and control & neutral & $\checkmark$ & conflictual \\
\hline Managerial hierarchy & neutral & $\checkmark$ & conflictual \\
\hline $\begin{array}{l}\text { Priority attention to the people who } \\
\text { control the critical resources }\end{array}$ & $\begin{array}{l}\text { neutral - } \\
\text { conflictual }\end{array}$ & $\checkmark$ & conflictual \\
\hline \multicolumn{4}{|l|}{ Co-operative } \\
\hline Voluntary and open membership & neutral & conflictual & $\checkmark$ \\
\hline Democratic member control & neutral & conflictual & $\checkmark$ \\
\hline $\begin{array}{l}\text { Member economic participation } \\
\text { required }\end{array}$ & neutral & neutral & $\checkmark$ \\
\hline $\begin{array}{l}\text { Co-operation among like-minded } \\
\text { organizations a commitment }\end{array}$ & neutral & $\begin{array}{l}\text { neutral- } \\
\text { conflictual }\end{array}$ & $\checkmark$ \\
\hline
\end{tabular}


Table 3: How the interactions between co-operatives of different types and their audiences shape identify formation

(in separate file) 
Figure 1: Propositions

(in separate file) 